\title{
2 Determination of Ambulance Abuse Level
}

\section{Turgut ŞAHİNÖZ1, Kadir ÇAVUŞ², Saime ŞAHINÖZ3,*, Melikşah TURAN" ${ }^{4}$}

1 Ordu University, Faculty of Health Sciences, Department of Health Management, Ordu, Turkey; drsahinoz@hotmail.com

2 Gümüşhane University, Faculty of Health Sciences, Department of Emergency and Disaster Management, Gümüşhane, Turkey; cvskadir08@gmail.com

3 Gümüşhane University, Faculty of Health Sciences, Department of Emergency and Disaster Management, Gümüşhane, Turkey; drsaime@hotmail.com

4 Gümüşhane University, Faculty of Health Sciences, Department of Emergency and Disaster Management, Gümüşhane, Turkey; shahturan@gmail.com

* Correspondence: drsaime@hotmail.com; Tel.: +905364334782

\begin{abstract}
Emergency Health Services refers to the urgent care. Ambulance abuse threaten the provision of proper health services and at the same time it affects the country's economy negatively. It was aimed to determine ambulance abuse level. This was a retrospective cohort research. In order to carry out our study, we analyzed 12,207 cases who called to the 112 Emergency Ambulance Services between 01.01.2016 and 31.12.2016. The data of the study has been obtained from the Emergency Health Automation System of the Provincial Health Directorate. According to preliminary diagnoses, traumatic cases were found to be $19.4 \%$ and cardiovascular cases were $12 \%$. According to the World Health Organization 32 Critical Code List $59.6 \%$ of the cases who called to the 112 Emergency Ambulance Services in 2016 were inappropriate. Ambulance abuse rate was $59.6 \%$. The high rate of misuse of 112 emergency ambulances affects the service flow and motivation of the staff negatively and causes extra financial burden. Thereof, awareness trainings should be given to the public and task and duties of the paramedics and emergency medical technicians who work at emergency ambulances should be expanded so that the transfer of unnecessary cases should be prevented.
\end{abstract}

Keywords: misuse, abuse, ambulance abuse, ambulances, emergency ambulances, Turkey

\section{Introduction}

Emergency Health Services refers to the urgent care cases that are provided to the patient during the whole process by the unified work of different departments that start at the scene and continue in the hospital environment $[1,2]$.

The emerging of 112 emergency medical services in our country was created in 1985 by the Ministry of Health at the main arteries of big cities in order to intervene traffic accidents which have serious traumatic urgency. Later, a system under the name of 077 was introduced and the infrastructure of 112 emergency medical services was established [3].

Despite the role and responsibilities of Emergency Health Services and the ambulance organizations involved in these services in providing remedial services for life threatening serious cases and serious injuries, the investigations found out that the group using emergency health services had mild illnesses and injuries in the form of low life risk [4].

It is expected that every patient that applies to ambulance organizations should be carefully evaluated. This situation has also supported improper use of emergency medical services [5]. Other 
reasons supporting inappropriate use of Emergency Health Services are inadequate education and social situations [6].

Abuses such as ambulance services threaten the provision of proper health services and at the same time it affects the country's economy negatively. Therefore, researches on Emergency Health Services are important [5].

It was aimed to determine ambulance abuse level.

\section{Materials and Methods}

This is a retrospective cohort study. In order to be able to carry out our study, necessary permissions were obtained from Gümüşhane Provincial Health Directorate. 12207 cases who applied between 01.01.2016 and 31.12.2016 to Gümüşhane 112 Emergency Ambulance Service were analyzed. Gümüşhane province is located in the North, in the Black Sea region of Turkey. Our study was carried out through a Microsoft Excel program via the Emergency Health Automation System from the Provincial Ambulance Service Headquarters of Gümüşhane Provincial Health Directorate.

\section{Results}

In our study, $50.8 \%$ of the cases that applied to Gümüşhane 112 Province Ambulance Service in 2016 year were identified as females and $49.2 \%$ were males.

Distribution of the cases in Gümüşhane province in year 2016 according to preliminary diagnosis is shown at Table 1.

Table 1. Distribution of the cases in Gümüşhane province in year 2016 according to preliminary diagnosis

\begin{tabular}{lll}
\hline Preliminary Diagnoses & Number & $\%$ \\
\hline Other & 3446 & 28.2 \\
Trauma & 2140 & 17.5 \\
Cardiovascular & 1471 & 12.0 \\
Gastrointestinal and metabolic & 1283 & 10.5 \\
Neurological & 1122 & 9.2 \\
Respiratory & 854 & 7.0 \\
Psychiatry & 814 & 6.7 \\
Infection & 513 & 4.2 \\
Genitourinary & 401 & 3.3 \\
Gynecology & 131 & 1.1 \\
Newborn & 32 & 0.3 \\
Total & 12207 & 100.0 \\
\hline
\end{tabular}

As it is seen in Table 1, it has been found out that traumatic cases with $19.4 \%$ are in the second place and cardiovascular cases in the third place with a rate of $12 \%$.

Assessment of the cases in Gümüşhane province in year 2016 through some vital findings is shown at Table 2.

Table 2. Assessment of the cases in Gümüşhane province in year 2016 through some vital findings 


\begin{tabular}{llllll}
\hline Open & 10796 & 98.2 & Regular & 10782 & 98.2 \\
Closed & 124 & 1.1 & No & 119 & 1.1 \\
Confused & 40 & 0.4 & Dispne & 31 & 0.3 \\
Conscious Blur & 19 & 0.2 & Irregular & 29 & 0.3 \\
Coma & 5 & 0.0 & Fast & 11 & 0.1 \\
Semi Coma & 1 & 0.0 & Superficial & 2 & 0.0 \\
Total & 10985 & 100.0 & Total & 10985 & 100.0 \\
\hline
\end{tabular}

As indicated in Table 2, at the conclusion of the clinical evaluations that the staff had done, $98.2 \%$ of the cases were found to be normal in terms of consciousness and only $1.8 \%$ were abnormal.

Distribution of cases in Gümüşhane province in year 2016 according to WHO critical code list is shown at Table 3.

Table 3. Distribution of cases in Gümüşhane province in year 2016 according to WHO critical code list

Distribution of cases according to WHO critical code list

1- Those who are not on the critical code list according to WHO

\begin{tabular}{ll} 
Number & $\%$ \\
\hline 7277 & 59.6 \\
1190 & 9.7
\end{tabular}

2- Myocardial infarction, arrhythmia, hypertension and severe 1190

3- Height fall, upper extremity fractures

4- Traffic accidents

6- Acute abdomen

367

7- Any situation that leads to loss of consciousness

301

8- High fever

9- Poisonings

10- Migraine or vomiting, headaches that develop with loss of consciousness

11- Sudden paralysis, Cerebrovascular episodes

12- Birth action that has begun

13- Spine and lower extremity fractures

15-Terrorism, sabotage, shooting, stabbing, fighting, beating,

16- Diabetic, uremic coma

17- Severe general condition disorder

18- Acute massive hemorrhages

19- Suicide attempt

20- Acute psychotic states

21- Serious burns

22- Serious eye injuries

23- Newborn comas

24- Serious allergy, anaphylaxis

25- Dialysis patient accompanied with generalized impairment

26- Freezing, cold impact

27- Drowning in water

28- Electric shock

29- Heat shock

30- Meningitis, encephalitis, brain abscess

31- Decompression 
89

As shown in Table 3, ambulance abuse level was 59.6\% in our province.

Distribution of cases in Gümüşhane province in year 2016 according to age groups is shown at Table 4.

Table 4. Distribution of cases in Gümüşhane province in year 2016 according to age groups

\begin{tabular}{|c|c|c|c|c|c|c|c|c|}
\hline \multirow{2}{*}{ Age Group } & \multicolumn{2}{|c|}{ Medical } & \multicolumn{2}{|c|}{ Trauma } & \multicolumn{2}{|c|}{ Unneeded } & \multicolumn{2}{|l|}{ Total } \\
\hline & $\mathrm{N}$ & $\%$ & $\mathrm{~N}$ & $\%$ & $\mathrm{~N}$ & $\%$ & $\mathrm{~N}$ & $\%$ \\
\hline $\begin{array}{l}\text { Newborn } \\
\text { and infant }\end{array}$ & 33 & 44.6 & 9 & 12.2 & 32 & 43.2 & 74 & 100.0 \\
\hline 1-8 & 116 & 36.3 & 78 & 24.4 & 126 & 39.4 & 320 & 100.0 \\
\hline $9-17$ & 236 & 23.3 & 182 & 17.9 & 596 & 58.8 & 1014 & 100.0 \\
\hline $18-29$ & 580 & 22.8 & 452 & 17.8 & 1515 & 59.4 & 2543 & 100.0 \\
\hline $30-40$ & 261 & 24.9 & 246 & 23.5 & 541 & 51.6 & 1048 & 100,0 \\
\hline $41-65$ & 812 & 33.3 & 452 & 18.5 & 1174 & 48.2 & 2438 & 100.0 \\
\hline $65+$ & 1170 & 33.0 & 300 & 8.5 & 2074 & 58.5 & 3544 & 100.0 \\
\hline Total & 3208 & 29.2 & 1719 & 15.7 & 6058 & 55.1 & 10985 & 100.0 \\
\hline
\end{tabular}

As indicated in Table 4, the groups with the most inappropriate ambulance usage were determined as 18-29, 9-17, 65+ age groups respectively.

\section{Discussion}

In the study we conducted, the other group was $28.2 \%$, traumatic cases were $17.5 \%$, cardiovascular diseases were $12.0 \%$, GIS and metabolic group were $10.5 \%$, while the cases presented in Emergency Medical Services would be examined according to the preliminary diagnoses. The other pre-diagnosis group includes cases which are not ill and cannot be pre-diagnosed, and occupy a small share within the other group.

In the study with reference to the 32 Critical Code List published by World Health Organization, ambulance abuse level was found to be $59.6 \%$, in other words, most of the cases taken by the ambulance were unnecessary for the purposes of ambulances. Another fact that supports the inappropriate use of ambulances is the stability of the vital findings of patients carried with ambulances.

We found out that the 65+ age group was in the first place with $32 \%$ and 3544 cases, followed by the $18-29$ age groups with $23.1 \%$ and 2543 cases. The increasing number of illnesses and the necessity of chronic diseases care led the need for emergency services and ambulance in the elderly to the first place [8].

We found out that age groups with the highest rate of ambulance abuse were 18-29, 9-17 and $65+$ age groups, respectively. Although we did not find any statistically significant difference between these groups ( $p=0.08$ ), we determined that the 18-29 age group was at the first order. This shows us that ambulance abuse begin at young ages. Again, this shows us that the problem is a fundamental problem and that the problem can be solved with the standard measures such as education and awareness-raising. It is thought that different systematic methods like home care, chronic care, policlinic transplantation and transportation for medical examination should be used as an alternative in order to reduce the high rate of ambulance abuse among elderly, because the transport process mainly takes place independently from life-threatening cases.

We determined in our study that $71.6 \%$ of the ambulance duties resulted in transfer to the hospital. This constitutes one of the reasons for excessive unnecessary loading in emergency departments.

According to Ayten et al.'s study in Denizli in 2015, the first group was other group with 25.7\%, the second group was traumatic cases with $22,7 \%$ and the cardiovascular system diseases with a rate of $19 \%$ [7]. 
According to a study conducted by Yaylacı and his colleagues in İstanbul in year 2013, among cases that ambulances went $36.8 \%$ of the cases were due to trauma in the first place, $16.9 \%$ in the second place due to infectious diseases, and $16.9 \%$ in the neurological preliminary diagnosis group out [8]. According to a study conducted by Benli and his colleagues in Karabük in year 2014, traumatic cases ranked first with $26.33 \%$, cardiovascular diseases with $19.45 \%$ and psychiatric diseases with $15.45 \%$ [9]. According to the survey conducted by Zenginol and his colleagues in Gaziantep in year 2011, traumatic cases with $29.80 \%$ were in the first place, cardiovascular system diseases with $19.14 \%$ in the second place and other group with $11.39 \%$ in the third place [10]. According to the research conducted by the Önge and their friends in Adana in year 2013, traumatic cases were the first with $28.4 \%$, neurological cases were second with $16.4 \%$ and cardiovascular cases followed with $14.2 \%$ [11].

When we examine the 112 Emergency Health Services in terms of the level of ambulance abuse in the light of the relevant data we see that one of the first studies on this subject was made in Birmingham, England, which had a population of 1200000 in the period that the research took place. In year 1980, Morris and colleagues found that the rate of ambulance abuse was 51.7\% [12]. Gardner and colleagues who carried out a similar research in the year 1990 found out that ambulance abuse was 62 [13]. According to a study conducted by Köse et al. in Van, it was determined that $88.4 \%$ of the patients who applied to the emergency service were discharged from the emergency service [14].

According to the study conducted by Atilla and his colleagues in İzmir in year 2010, it was determined that $53.6 \%$ of the patients were discharged from the emergency service [15]. According to the research conducted by Ayten in year 2015, 97\% of the calls to Denizli's 112 in year 2012 and 94\% in year 2013 were unsubstantial and inappropriate calls [7]. According to a research conducted in İstanbul in year 2013, Yaylacı and his colleagues have found out that ambulance abuse rate was $37.7 \%$ [8]. In the study conducted by Duran in Kayseri in year 2015, ambulance abuse rate was determined as 59\% [16]. In year 2017, Silibolatlaz found in Adana that the rate of ambulance abuse was $53.7 \%$ and $78 \%$ of the patients were discharged without hospitalization from emergency service [17].

Kidak and his colleagues examined the distribution of cases according to age groups in their study conducted in İzmir province and determined that the first group was $65+$ age group with $26.7 \%$ [18]. Aydin et al. found out in the study they have conducted that, over 60 years old group was the first with a rate of $24 \%$ and the 20-29 age group was in the second place with $22 \%$ [19]. Zenginol et al. has found out that the age group of 65 years was in the first place with $17.9 \%$ and the group of $16-25$ years was in the second place with $17.8 \%$ [10].

Yaylacı and colleagues determined that the average age of the patients who were considered as urgent was found to be $54.31 \%$ and the average age of the patients not accepted as urgent was $38.07 \%$ in their survey [8].

Our study is similar to the studies conducted in our country and worldwide. Whether in our country or in the world, ambulance abuse is a current problem [20]. Despite the increasing capacity of Emergency Health Services and Ambulances every year, studies have not found any positive development towards ambulance abuse. This situation emerges as a situation that needs to be overcome in our country. Ambulance abuse results in worn out personnel in the professional sense, adverse effects on service flow, economic burden on the country.

In a study conducted by Greenhalgh et al. it has been found out that subject to further empirical testing, nonadoption, abandonment, scale-up, spread, and sustainability (NASSS) could be applied across a range of technological innovations in health and social care [21].

The Prime Ministry circular issued on 9 August 2010 states that regardless of having any social security and what kind of social security they have the people applying to the private or public health institutions in life-threatening emergency situations should be treated free of charge [22].

Authors should discuss the results and how they can be interpreted in perspective of previous studies and of the working hypotheses. The findings and their implications should be discussed in the broadest context possible. Future research directions may also be highlighted. 
In the study with reference to the 32 Critical Code List published by World Health Organization, ambulance abuse was found to be $59.6 \%$. As stated in our study and in other studies, the high rate of use out of the emergency has revealed ambulance abuse. One of the preventive measures in this situation might be that people who do not have an ambulance indication may be charged additional fees. In order to prevent ambulance abuse, public awareness trainings should be implemented and the task definitions and duties of the emergency medical technicians and paramedics who work in ambulances should be expanded so that they can prevent the transfer of unnecessary cases.

Author Contributions: conceptualization, T.Ş., K.Ç., S.Ş. and M.T.; methodology, T.Ş., K.Ç., S.Ş. and M.T.; software, T.Ş., K.Ç., S.Ş. and M.T.; validation, T.Ş., K.Ç., S.Ş. and M.T.; formal analysis, T.Ş., K.Ç., S.Ş. and M.T.; investigation, T.Ş., K.Ç., S.Ş. and M.T.; resources, T.Ş., K.Ç., S.Ş. and M.T.; data curation, T.Ş., K.Ç., S.Ş. and M.T.; writing-original draft preparation, T.Ş., K.Ç., S.Ş. and M.T.; writing-review and editing, T.Ş., K.Ç., S.Ş. and M.T.; visualization, T.Ş., K.Ç., S.Ş. and M.T.; supervision, T.Ş., K.Ç., S.Ş. and M.T.

Funding: This research received no external funding

Acknowledgments: None

Conflicts of Interest: The authors declare no conflict of interest.

\section{References}

1. T.C. Official Newspaper. Emergency Health Services Regulation. 22 May 2014, issue: 29007. Prime Ministry Printing House, Ankara.

2. Soysal S, Karcioğlu Ö ve Topaçoğlu H. Emergency Medical Systems. Cerrahpaşa Medical Journal. 2003; 34(1):51-57.

3. Paksoy VM. Comparison of international application models in emergency health services: AngloAmerican and Franko-German model. T.C. Journal of T.C. İnönü University Health Services Vocational School. 2016; 5(7):1-15.

4. Webb SB Jr and Christoforo J. The use and misuse of ambulance services by the emergency department at the hospital of St. Mary's hospital. Raphael. Connecticut Medicine 1974; 38(4):195-198.

5. Morgans A and Burgess S. Judging a patient's decision to seek emergency healthcare: clues for managing patient demand. Australian Health Review 2012; 36(1):110-114. PMID:22513030 DOI:10.1071/AH10921

6. Gerson LW and Skvarch L. Emergency medical service utilization by the elderly. Annals of Emergency Medicine1982;11(11):610-612. PMID:7137669

7. Ayten S. Evaluation of the use of search and emergency ambulance services in 112 command centers in Denizli province. doctoral thesis, Faculty of Medicine, Pamukkale University, 2015.

8. Yaylacı S, Cimilli Öztürk T ve Çelik Yılmazer S. Retrospective evaluation of the urgency of the patients who applied to emergency ambulance. Acıbadem Üniversitesi Sağlık Bilimleri Dergisi 2013;4(2):64-67.

9. Benli AR, Koyuncu M, Cesur Ö, Karakaya E, Cüre R and Turan MK. Evaluation of use of the 112 emergency ambulance service in Karabük city. Journal of Clinical and Analytical Medicine 2014;10:1-4.

10. Zenginol M, Al B, Genç S, Deveci İ, Yarbil P, Yılmaz D ve ark. Three year study results of 112 emergency ambulances in Gaziantep province. Journal of Academic Emergency Medicine 2011;10(1):27-32.

11. Önge T, Satar S, Kozacı N, Açıkalın A, Köseoğlu Z, Gülen M, et al. Analysis of Patients Admitted to the Emergency Medicine Department by the 112 Emergency Service. JAEM 2013;12(3):150-154.

12. Morris DL and Cross AB. "Is the emergency ambulance service abused?" Br Med J 1980:121-123.

13. Gardner GJ. The use and abuse of the emergency ambulance service: some of the factors affecting the decision whether to call an emergency ambulance. Emergency Medicine Journal 1990;7(2):81-89. PMID:2390158 PMCID:PMC1285673

14. Köse A, Köse B, Öncü MR and Tuğrul F. The appropriateness of the profile of the patients attending to a state hospital emergency service and the application. Gaziantep Med J 2011;17(2):57-62.

15. Atilla ÖD, Oray D, Akın S, Acar K ve Bilge A. An Emergency Department perspective: Ambulance transfers and referral consents of the patients. Turk J Emerg Med 2010;10(4):175-180.

16. Duran M. Kayseri 112 emergency health services 2013 year case analysis. Doctoral Thesis in Medicine, $\mathrm{T}$. C. Erciyes University Faculty of Medicine Department of Emergency Medicine, Kayseri, 2015.

17. Silibolatlaz A. 112 assessment of the emergency situations of the patients in the emergency department with ambulances. Doctoral Thesis in Medicine, T. C. Ministry of Health, Health Sciences University Turkey 
Public Hospitals Association, Adana Province General Secretary, Adana Numune Education and Research Hospital Emergency Medicine Clinic, Adana, 2017.

18. Kıdak L, Keskinoglu P, Sofuoğlu T ve Ölmezoğlu Z. Evaluation of the use of 112 emergency ambulance services in the province of İzmir. General Medicine Journal 2009;19(3):113-19.

19. Aydın T, Akköse Aydın ŞA, Köksal Ö, Özdemir F, Kulaç S ve Bulut M. Evaluation of Features of Patients Attending the Emergency Department of Uludag University Medicine Faculty Hospital and Emergency Department Practices. JAEM 2010: 163-8.

20. Richards JR and Ferrall SJ. Inappropriate use of emergency medical services transport: comparison of provider and patient perspectives. Academic Emergency Medicine 1999;6 (1):14-20. PMID:9928971

21. Greenhalgh T, Wherton J, Papoutsi C, Lynch J, Hughes G, A'Court C, et al. Beyond Adoption: A New Framework for Theorizing and Evaluating Nonadoption, Abandonment, and Challenges to the Scale-Up, Spread, and Sustainability of Health and Care Technologies. Journal of medical Internet research 2017 Nov 1;19(11):e367. PMID:29092808 PMCID: PMC5688245 DOI:10.2196/jmir.8775

22. Emergency health services presentation Prime Ministry Circular. http://dosyamerkez.saglik.gov.tr/eklenti/2528,2010-16-acil-saglik-hizmetlerinin-sunumu. 10 August 2010. 